\section{Removal of a migrated covered metallic stent through an esophageal stricture, with multiple endoloops}
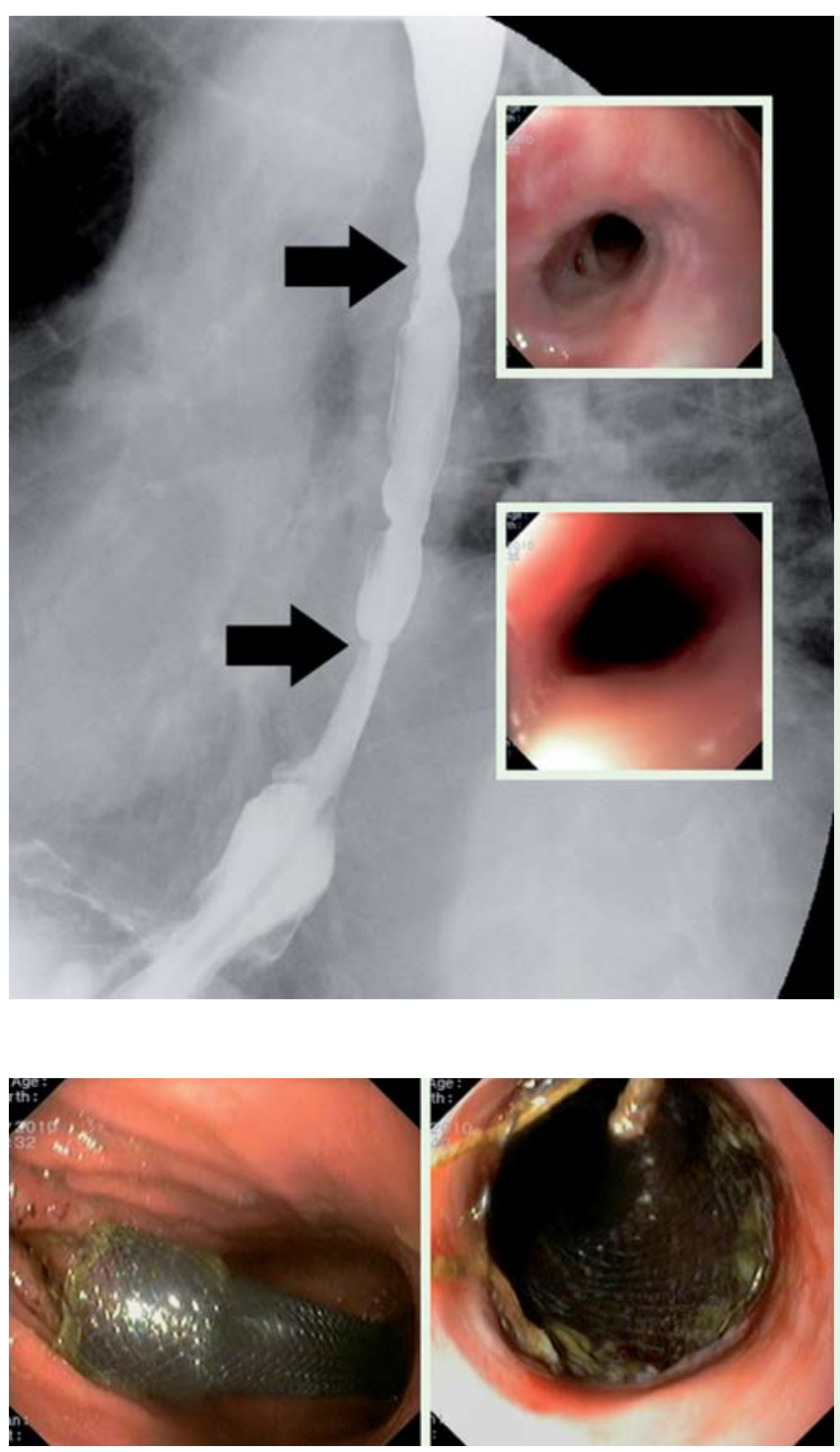

Fig. 2 Covered metallic stent migrated into the stomach (left). The upper mesh could not be passed through the distal esophageal stricture despite gentle traction on the nylon loop (right).
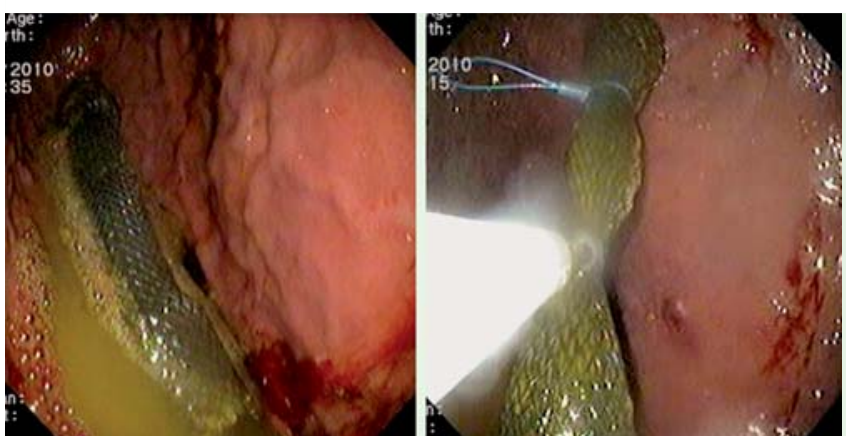

Migration is a common delayed complication $(3 \%-14 \%)$ following deployment of an esophageal self-expandable metallic stent (SEMS) [1]. Although removal of migrated SEMS in the stomach is recommended to avoid gastrointestinal complications such as bleeding, obstruction, and perforation, this can be technically challenging.

A 52-year-old man was referred to our center for progressive dysphagia following a caustic injury, which was refractory to multiple balloon dilations carried out in the past two years. On esophagoscopy, a 3-mm stricture at $25 \mathrm{~cm}$ from the incisors could not be passed. A barium swallow showed another severe esophageal stricture at $34 \mathrm{~cm}(\bullet$ Fig. 1$)$ from the incisors.

A fully covered stent with internal and external silicone coating (Evolution, $10 \mathrm{~cm}$, Cook Medical, Limerick, Ireland) was deployed under fluoroscopic guidance without complications. The patient improved notably after this procedure. At 1 month, endoscopy revealed that the stent had migrated. The esophageal caliber was significantly increased but resistance was encountered when passing a 9.2-mm endoscope across both stenoses ( $\mathbf{F i g} \mathbf{1}$ ). The prosthesis was found to be located along the great curvature of the antrum, however, removal by grasping the nylon loop attached to the proximal end of the stent was not possible through the distal stricture ( $\bullet$ Fig. 2 ).

Hence four detachable ligating devices (Polyloop, HX-400U-30, Olympus, Barcelona, Spain) were used to squeeze the SEMS and reduce its radial force ( Fig. 3 ). This maneuver allowed the prosthesis to be easily removed through both strictures. At 6 months' follow-up, the patient had gained $5 \mathrm{~kg}$ in weight and was tolerating a solid diet.

There are anecdotal reports of the usefulness of endoloops to extract migrated esophageal SEMS [2 -4]. SEMS are currently indicated not only for malignant but also benign strictures, so it is anticipated that the number of SEMS being used and potentially migrating will increase [1]. Awareness of the technique described in this report will enhance the endoscopist's armamentarium when faced with this complication.

Competing interests: None

Endoscopy_UCTN_Code_TTT_1AO_2AZ 


\section{J. Molina-Infante, M. Fernandez- Bermejo, B. Perez-Gallardo}

Unit of Gastroenterology, Hospital San Pedro de Alcantara, Caceres, Spain

\section{References}

1 Siersema PD. Stenting for benign esophageal strictures. Endoscopy 2009; 41: 363-373

2 Seitz U, Thonke F, Bohnacker S et al. Endoscopic extraction of a covered esophageal Z-stent with the aid of endoloops. Endoscopy $1998 ; 30: S 91$
3 De Ronde T, Martinet JP, Melange M. Easy removal of migrated self-expanding esophageal metal stent using an endoloop device. Gastrointest Endosc 2000; 52: 125-127

4 An HJ, Lee HY, Kim BW et al. Endoscopic removal of a migrated esophageal self-expandable metal stent after compression with detachable snares through an intact esophageal stent. Gastrointest Endosc 2010; 71: 205-207

\section{Bibliography}

DOI $10.1055 / \mathrm{s}-0030-1255768$

Endoscopy 2010; 42: E268 -E269

(c) Georg Thieme Verlag KG Stuttgart · New York . ISSN 0013-726X

\section{Corresponding author}

\section{J. Molina Infante}

Unit of Gastroenterology

C/ Pablo Naranjo s/n

10003 Caceres

Spain

Fax: +34-927251545

xavi_molina@hotmail.com 